\title{
Inspiring staff to deliver excellent customer service: the influence of CSR and flexible leadership styles
}

Many companies would claim that their people are their greatest asset. Those that are not in a position to make such a claim should arguably be looking at ways to develop their staff and get better performance out of them. You can put in place excellent systems but if the people putting those systems into practice are demotivated then you still have a problem. Happy the firm that has a workforce who take ownership of their customer relationships, take pride in their work and look for ways to "go the extra mile" to rescue service failures and transform difficult situations into satisfied customers and retained business. So how do you go about creating such a workforce?

\section{The study}

This is a question that Luu et al. (2019) set out to consider. They focus on the ways CSR and flexible leadership styles can positively influence behaviors amongst employees relating to service recovery and customer-focused organizational citizenship. They concentrate on the tourist industry in Ho Chi Minh City, Vietnam. This location makes for an interesting site for a study relating to customer retention. The authors note that $13 \mathrm{~m}$ people visit the country each year but sadly the numbers returning for subsequent visits are poor. Data from employees and their managers in just over 30 tour companies - each with no fewer than 100 staff members - provided some strong indicators for firms looking to develop positive behaviors amongst employees in customer-facing areas.

In short, the authors investigated the ways in which:

- CSR influences the behavior of staff with respect to customers and levels of service recovery.

- What effect the ability of employees to "craft" their own roles in respect to customer service has on the interplay between CSR and these areas.

- Whether effectively-flexed managerial approaches reduce the influence of CSR.

Lots of research has gone into why it is beneficial for firms to adopt a genuine and strong CSR strategy in a world where trust in business has so often been shaken. It would seem therefore to be an additional point in favor of CSR if it also leads to greater commitment from employees - why should this be the case?

\section{The role of CSR}

Reviewing the literature in this field the authors point out that firms with strong CSR values focus on the needs and interests of both internal and external stakeholders. They therefore equip their teams with the resources they need to provide excellent customer service - the right training, clear guidance and help where required, for example. More than this though they can embed a strong sense of purpose in their staff stemming through association with these values. These people tend to be proud of working

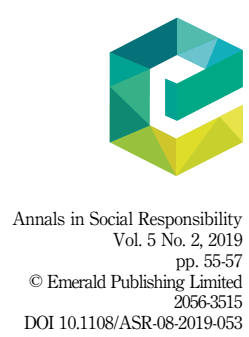


ASR

5,2

for such an organization and that strong connection to the business feeds into positive engagement with customers and a desire to resolve any problems those customers are facing. That sort of attitude will have a tendency to exist throughout the firm and this provides for a supportive environment of colleagues sharing the same approach to their customer-facing relationships.

\section{Job development}

On one level staff members in these types of firms will be well set to provide a great service to their customers. Furthermore, however, such employees have the capability and motivation needed to reflect on their own roles and resources and to develop them in order to better meet customer needs - "job crafting" as described in the article. The authors cite four aspects of this as described by Tims and Bakker (2010). These focus on:

(1) accessing and building on the information needed to develop in the role;

(2) utilizing input from fellow workers and management within the firm;

(3) increasing the nature and value of the role; and

(4) removing barriers and negative factors preventing excellent performance.

In short staff members engaged in this kind of activity are taking ownership of their jobs and dynamically building their capacity to serve customers well by seeking out the information they need, broadening out their activities within the firm and identifying/ removing blockers that would otherwise hold them back.

\section{Flexible leadership styles}

Luu et al. also consider the role of management in all of this. They refer to "ambidextrous" leadership as an approach which involves flexing of two managerial styles. The first of these involves encouraging employees to think freely, ask questions and crucially provide an environment where workers have the support they need to do so. The second style is much more focused on ensuring efficient, disciplined, effectively measured activities and processes to ensure the smooth running of the organization. The key element for managers is the ability to identify which approach is the best fit for the circumstances at play at any given time. Where this kind of leadership features within the company there are implications with respect to the role of CSR in influencing employee behavior - i.e. workers will be able to draw more directly from their leadership. Where such leadership is not in place this of course is not an option and they will draw more directly from the CSR values of the firm.

\section{Action points for managers}

What does this mean for managers? The authors point out that firms should adopt and use effectively these flexible management approaches but also understand the importance of CSR in influencing positive behaviors in relation to customer service. Not only does this require solid CSR approaches but also a communication strategy that will ensure staff understand the firm's CSR values. With this in place and a supportive environment with respect to employees developing their own roles a firm is well placed to provide better customer service. Not only that but they will have a well-motivated and dynamic workforce. 
Comment

The review is based on "Corporate social responsibility, ambidextrous leadership, and service excellence” by Tuan Luu et al. (2019).

\section{References}

Luu, T., Le, V., Masli, E. and Rajendran, D. (2019), "Corporate social responsibility, ambidextrous leadership, and service excellence”, Marketing Intelligence \& Planning, Vol. 37 No. 5, pp. 580-594, available at: https://doi.org/10.1108/MIP-05-2018-0157

Tims, M. and Bakker, A.B. (2010), "Job crafting: towards a new model of individual job redesign", SA Journal of Industrial Psychology, Vol. 36 No. 2, pp. 1-9.
Influence of CSR and flexible leadership styles 